\title{
Effects of Exposure to Estradiol Benzoate or Flutamide at the Weaning Age on Expression of Connexins in the Caudal Epididymis of Adult Rat
}

\author{
${ }^{\dagger}$ Ki-Ho Lee \\ Department of Biochemistry and Molecular Biology, College of Medicine, Eulji University, Daejeon 301-746, Korea
}

\begin{abstract}
The present research was chiefly designed to determine the effect of the treatment of estrogenic agonist, estradiol benzoate (EB), or antiandrogenic compound, flutamide (Flu), at the weaning age on the expression of connexin $(C x)$ isoforms in the caudal epididymis of adult male rat. Animals were subcutaneously administrated with a single shot of either EB at a low-dose (0.015 $\mu \mathrm{g}$ of $\mathrm{EB} / \mathrm{kg}$ body weight $(\mathrm{BW}))$ or a high-dose $(1.5 \mu \mathrm{g}$ of EB/kg BW) or Flu at a low-dose $(500 \mu \mathrm{g}$ of EB/kg BW) or a high-dose (5 mg of $\mathrm{EB} / \mathrm{kg} \mathrm{BW}$ ). Expressional changes of $C x$ isoforms in the adult caudal epididymis were examined by quantitative real-time PCR analysis. The treatment of a low-dose EB caused significant increases of $C \times 30.3, C x 31, C \times 32$, and $C x 43$ transcript levels but reduction of $C \times 31.1$, $C x 37$, and $C x 45$ expression. Exposure to a high-dose EB resulted in very close responses observed in a low-dose EB treatment, except no significant expressional change of $C x 37$ and a significant induction of $C x 40$. Expression of all $C x$ isoforms, except $C x 45$, was significantly increased by a low-dose Flu treatment. Expressional increases of all $C x$ isoforms were detected by a high-dose Flu treatment. The current study demonstrates that a single exposure to estrogenic or antiandrogenic compound during the early postnatal developmental period is sufficient to disrupt normal expression of $C x$ isoforms in the adult caudal epididymis.

Key words : Connexin, Estradiol benzoate, Flutamide, Real-time PCR, Gene expression, Caudal epididymis
\end{abstract}

\section{INTRODUCTION}

The epididymis is a part of the excurrent duct of male reproductive tract and is the place in which sperm becomes acquiring fertilizing capacity (Robaire \& Hermo, 1988). The epididymis is structurally and functionally separated into 4 different regions, including initial segment, caput epididymis, corpus epididymis, and caudal epididymis (Robaire \& Hermo, 1988). Among these regions of the epididymis, the caudal epididymis plays an important role for storage and quiescence of mature sperm (Robaire \& Hermo, 1988). Thus, it is fully reasonable to consider that functional regulation of the caudal epididymis could give an influence on the male reproductive ability.

Like the other parts of the epididymis, the caudal epididymis has a layer of epithelial cells which faces the luminal space and is surrounded by multiple smooth muscle layers (Robaire et al., 2006). However, the caudal epididymis has different structural and histological features, compared with other compartments of the epididymis (Robaire et al., 2006). For examples, luminal diameter of the caudal epididymis is wider than the caput and corpus epididymis (Robaire et al., 2006). The highest proportion of the principal cells within the epididymal epi-

\footnotetext{
Manuscript received October 24, 2016, Received in revised form November 22, 2016, Accepted December 17,2016

† Corresponding Author : Ki-Ho Lee, Ph.D. Department of Biochemistry and Molecular Biology and Medical Sciences Research Institute, Eulji University, Daejeon 301-746, S. Korea. Tel: +82-42-259-1643, Fax: +82-42-259-1649, E-mail: kiholee@eulji.ac.kr

This is an Open Access article distributed under the terms of the Creative Commons Attribution Non-Commercial License (http:// creativecommons.org/licenses/by-nc/3.0) which permits unrestricted non-commercial use, distribution, and reproduction in any medium, provided the original work is properly cited.
} 
thelium is found in the caudal epididymis (Robaire et al., 2006). Even though the clear cells, a cell type found in epididymal epithelium, are also present in the caput, corpus, and caudal epididymis, apical cells and narrow cells are absent or scare in the caudal epididymis (Robaire et al., 2006). It is relatively well determined that each cell type within the epididymal epithelium has unique structural characteristics and histological features, relating with its functions (Robaire et al., 2006). Therefore, it is proposed that functional regulation of different epididymal compartments is, in part, governed by behavioral modulation of epithelial cells.

The functions of cells in an animal tissue having multicellular types, such as the epididymis, could be regulated by direct cell-cell communication via connexin $(C x)$-based gap junction linking adjacent cells (Lawrence et al., 1978). Exchanges of ions, small metabolites, and second messengers between neighboring cells are allowed through the gap junction (Valiunas et al., 2005). Gap junction is structurally consisted of $6 C x \mathrm{~s}$, and there are at least $21 C x$ isoforms found in vertebrates (Goodenough \& Paul, 2009). Expression of several $C x$ isoforms has been found in many types of mammalian tissues and even a specific cell type (Goodenough \& Paul, 2009). In case of the epididymis, the presence and expression of 8 to 9 different $C x$ isoforms have been identified from our earlier researches and others (Cry, 2011; Lee, 2013; Seo et al., 2010). Also, the expression of $C x$ isoforms in the epididymis is segmentalspecific and/or postnatal development age-specific (Lee, 2013; Seo et al., 2010). Even though Cry et al (1996) has demonstrated the presence of $C x 43$ in the base of the epithelium between basal and principal cells in the rat epididymis, little information is available for the localization of other $C x$ isoforms in the epididymis.

Expressional regulation of $C x$ isoforms in the epididymis has been examined in our previous studies and others. St-Pierre et al (2003) have shown the drastic decrease of
Cx43 expression in the initial segment, caput epididymis, and corpus epididymis, but not in the caudal epididymis by propylthiouracil-induced hypothyroidism at the neonatal age. Exposure to estradiol benzoate (EB), an estrogen agonist, or flutamide (Flu), an antiandrogenic compound, at the neonatal or weaning age results in aberrant expression of several $C x$ isoforms in the initial segment and corpus epididymis of the adult rat (Lee, 2014, 2015a, Lee, 2015b). However, it is notable that the expressional changes of $C x$ isoforms induced by EB or Flu treatment are different in each epididymal segment and/or a type of the treatment (Lee, 2014, 2015a, 2015b). Moreover, expressional patterns of $C x$ isoforms in a given region of the adult epididymis differ with the time of exposure to EB or Flu during postnatal period (Lee, 2014, 2015a). Most recently, our research has demonstrated expressional changes of $C x$ isoforms in the adult caudal epididymis administrated with EB or Flu at the early neonatal age (Lee, 2016). From these observations, it has been suggested that the exposure to EB or Flu at the different postnatal age would result in alternation of gene expression of $C x$ isoforms in the adult caudal epididymis. Thus, the present research was designed to examine the expressional change of $C x$ isoforms in the caudal epididymis of the adult rat treated with EB or Flu at the weaning age.

\section{MATERIALS AND METHODS}

\section{Animals and experimental design}

Pregnant female Spragure Dawley rats were purchased from Samtako (OSan, Korea) and were individually caged. Each female rat was randomly assigned into one of five experimental groups; a control, a low-dose estradiol benzoate (EB)-treated (EB-L, $0.015 \mu \mathrm{g}$ of EB/kg body weight (BW)), a high-dose EB-treated (EB-H, $1.5 \mu \mathrm{g}$ of EB/kg BW), a low-dose flutamide (Flu)-treated (Flu-L, $500 \mu \mathrm{g}$ of Flu/kg BW), or a high-dose Flu-treated (Flu-H, $5 \mathrm{mg}$ of 
$\mathrm{Flu} / \mathrm{kg} \mathrm{BW}$ ) group. For each experimental group, five to seven male pups obtained from the delivery of the female rats were used for the present research. Experimental animals were allowed to freely access to drinking water and food for entire experiment period.

Once the experimental animal became at the weaning age, a vehicle (peanut oil) or a chemical compound was subcutaneously administrated into the animal. To prepare the EB or Flu solution, the EB and Flu powder purchased from Tokyo Chemical Industry Co. (Tokyo, Japan) was first completely dissolved in $100 \% \mathrm{EtOH}$, and then the $\mathrm{EB}$ or Flu solution was diluted in peanut oil. At the weaning age, body weight of the experimental animal was measured, and the amount of EB or Flu solution to be injected was calculated. The injected volume of EB or Flu solution didn't exceed $0.05 \mathrm{~mL}$. A total of 31 male rats were used for this study, including control group $(n=5)$, EB-L group $(n=7)$, EB-H group $(n=7)$, Flu-L group $(n=6)$, and Flu-H group $(n=6)$. The present study was carried out in accordance with the guide for the care and use of laboratory animals of National Research Council in S. Korea.

\section{Tissue collection and isolation of total RNA}

The tissue was isolated from the experimental animals at 4 months of postnatal age. First, the animals were euthanized by $\mathrm{CO}_{2}$ stunning, and then an incision on lower abdomen was made with a pair of scissors. The male reproductive tract was taken from the animal and was placed in the cold PBS solution. The testis and epididymal fat were separated from the epididymis, and the epididymis was quickly dissected into four different regions, such as initial segment, caput epididymis, corpus epididymis, and caudal epididymis. Each part of the epididymis was rinsed in fresh cold PBS solution and rapidly frozen in liquid nitrogen. The tissue was stored in $-80^{\circ} \mathrm{C}$ until used for the isolation of total RNA.

The extraction of total RNA from collected caudal epi- didymis was carried out as following. The tissue was homogenized in total RNA extraction solution (iNtRON Biotech, Sungnam, Korea) with a homogenizer (Fisher Scientific, Pittsburgh, PA). Total RNA precipitated by isopropanol was washed with 70\% DEPC-treated EtOH , and air-dried total RNA pellet was resuspended in DEPCtreated RNase-free $\mathrm{dH}_{2} \mathrm{O}$. The concentration and ratio of total RNA were measured with NanoDrop Lite spectrophotomer (Thermo Scientific, Wilmington, DE). One microgram of total RNA was used to determine the quality of the total RNA sample by agarose gel electrophoresis.

\section{3. cDNA construction and quantitative real-time} PCR analysis

One microgram of total RNA was utilized to construct the first-stranded cDNA with oligo-dT primer and ImProm-II ${ }^{\mathrm{TM}}$ reverse transcription system (Promega, Madision, WI). The reaction of reverse transcription was performed in a sequential process of $25^{\circ} \mathrm{C}$ for $5 \mathrm{~min}, 42^{\circ} \mathrm{C}$ for $90 \mathrm{~min}$, and $70^{\circ} \mathrm{C}$ for $15 \mathrm{~min}$. Generated cDNA was directly utilized for quantitative real-time PCR analysis. Table 1 shows detailed information of oligonucleotide primers used for quantitative real-time PCR.

To conduct the quantitative real-time PCR, a mixture of $1 \mu \mathrm{L}$ cDNA, 10 pmol primer set, $10 \mu \mathrm{L}$ PCR master mixture (Finnzymes, Espoo, Finland), and DNase-free $\mathrm{dH}_{2} \mathrm{O}$ to make a total volume of $20 \mu \mathrm{L}$ was prepared for PCR analysis. The PCR condition was as followings; a pre-denaturation step at $95^{\circ} \mathrm{C}$ for $30 \mathrm{sec}, 40$ cycles of denaturation at $95^{\circ} \mathrm{C}$ for $30 \mathrm{sec}$, annealing at $\mathrm{T}_{\mathrm{m}}$ for $30 \mathrm{sec}$, and extension at $72^{\circ} \mathrm{C}$ for $30 \mathrm{sec}$. Cyclophilin A (Ppia) was included for a quality internal control of PCR. The sizes of all PCR products were checked with the electrophoresis in $1.2 \%$ agarose gel.

\section{Presentation and statistical analysis of data}

A mean and a standard error of an experimental group 
Table 1. Oligonucleotide primers for real-time PCR analysis

\begin{tabular}{|c|c|c|c|}
\hline $\begin{array}{c}\text { Gene } \\
\text { (GenBank ID) }\end{array}$ & $\begin{array}{l}\text { Primer sequence } \\
\qquad\left(5^{\prime} \rightarrow 3^{\prime}\right)\end{array}$ & $\begin{array}{l}\mathrm{T}_{\mathrm{m}} \\
\left({ }^{\circ} \mathrm{C}\right)\end{array}$ & $\begin{array}{c}\text { PCR product } \\
\text { size (bps) }\end{array}$ \\
\hline $\begin{array}{c}C \times 26 \\
\left(\mathrm{NM} \_001004099\right)\end{array}$ & $\begin{array}{l}\text { (F) ТCCTCTTCATCTTCCGCATC } \\
\text { (R) CCGTTTCTTTTCGTGTCTCC }\end{array}$ & 55 & 233 \\
\hline $\begin{array}{l}\text { Cx30.3 } \\
(\text { NM_053984) }\end{array}$ & $\begin{array}{l}\text { (F) CCCAATGTCTGCTATGACGA } \\
\text { (R) CACAGCAGCCTTGAAGATGA }\end{array}$ & 57 & 243 \\
\hline $\begin{array}{c}C \times 31 \\
\left(\mathrm{NM} \_019240\right)\end{array}$ & $\begin{array}{l}\text { (F) TTGAGCGGTGTGAACCAGTA } \\
\text { (R) TGTTGGAGATGGGGAAGAAG }\end{array}$ & 57 & 193 \\
\hline $\begin{array}{c}\text { Cx31.1 } \\
(\mathrm{NM}+019241)\end{array}$ & $\begin{array}{l}\text { (F) CATCGTCTGCATCCTGCTTA } \\
\text { (R) ATGAGGTCGCTTGAGAGGAA }\end{array}$ & 55 & 165 \\
\hline $\begin{array}{c}C x 32 \\
\left(\mathrm{NM} \_017251\right)\end{array}$ & $\begin{array}{l}\text { (F) AGAATCATGGTGCTGGTGGT } \\
\text { (R) CCTCAAGCCGTAGCATTTTC }\end{array}$ & 57 & 235 \\
\hline $\begin{array}{c}C \times 37 \\
\left(\mathrm{NM} \_021654\right)\end{array}$ & $\begin{array}{l}\text { (F) AGTGTCTGTACCTTGGATGCC } \\
\text { (R) CAGCACACTTAGCCAAGAGC }\end{array}$ & 51 & 223 \\
\hline $\begin{array}{c}C x 40 \\
\left(\mathrm{NM} \_019280\right)\end{array}$ & $\begin{array}{l}\text { (F) ATACCATTCAGCCTGGTTGC } \\
\text { (R) CGGCCTCTTTAGCTTTCTCA }\end{array}$ & 57 & 189 \\
\hline $\begin{array}{c}C x 43 \\
\left(\mathrm{NM} \_012567\right)\end{array}$ & $\begin{array}{l}\text { (F) AGCAAGCTAGCGAGCAAAAC } \\
\text { (R) GAGTTCATGTCCAGCAGCAA }\end{array}$ & 55 & 151 \\
\hline $\begin{array}{c}C x 45 \\
\left(\mathrm{NM} \_001085381\right)\end{array}$ & $\begin{array}{l}\text { (F) GATCATCCTGGTTGCTACTC } \\
\text { (R) GATCCTCTTCATGGTCCTCT }\end{array}$ & 51 & 173 \\
\hline $\begin{array}{c}\text { Ppia } \\
\text { (NM_07101.1) }\end{array}$ & $\begin{array}{l}\text { (F) GGCAAATGCTGGACCAAACAC } \\
\text { (R) TTAGAGTTGTCCACAGTCGGAGATG }\end{array}$ & 59 & 196 \\
\hline
\end{tabular}

$C x$ : connexin; Ppia : peptidylprolyl isomerase A (cyclophilin A).

were obtained from the data of independently triplicated reverse transcription reaction and PCR. The data represent the relative expressional ratio between Ppia and target $C x$ isoform. Statistical differences of $C x$ expressional levels among EB or Flu treatment groups and control group were determined by one-way ANOVA, if necessary, followed by Duncan's test. Once $p<0.05$, it was considered the presence of statistical significances among experimental groups.

\section{RESULTS}

1. Expressional changes of $C \times 26$ and $C \times 30.3$ genes in the adult caudal epididymis treated with EB or flutamide at the weaning age

Expression of $C x 26$ was significantly increased by EB treatment, even though there was no significant difference on EB-induced transcript level of $C x 26$ gene between a 
(A)

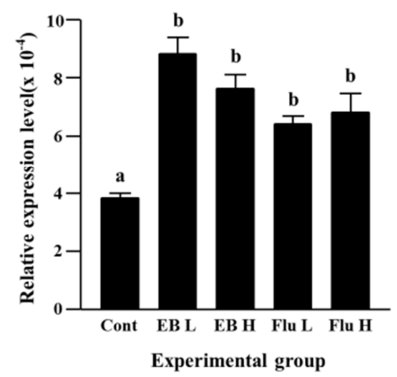

(B)

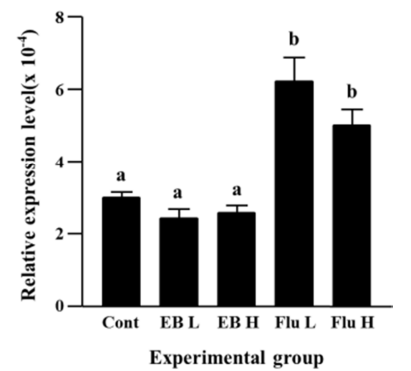

Fig. 1. Expressional changes of $C x 26$ and $C x 30.3$ in the caudal epididymis of adult rat treated with estradiol benzoate (EB) or flutamide (Flu) at the weaning age. Animals were subcutaneously injected with EB at a low dose $(0.015 \mathrm{mg} / \mathrm{kg}$ body weight, EB-L) or a high dose $(1.5 \mathrm{mg} / \mathrm{kg}$ body weight, EB-H) or Flu at a low dose $(500 \mathrm{mg} / \mathrm{kg}$ body weight, Flu-L) or at a high dose $(50 \mathrm{mg} / \mathrm{kg}$ body weight, Flu-H) at the weaning age. Control animals (Cont) were administrated with peanut oil. Different letters indicate statistical differences among control group and experimental groups in EB or Flu treatment group on transcript levels of $C \times 26$ (A) or $C x 30.3(\mathrm{~B})$

low-dose treated group and a high-dose treated group (Fig. 1A). Induction of $C x 26$ gene expression was also observed in flutamide-treated groups (Fig. 1A). However, the increment of $C \times 26$ transcript by the treatment of a low-dose flutamide was not significantly different with that by the treatment of a high-dose flutamide (Fig. 1A).

No significant change of $C \times 30.3$ transcript level was detected by EB treatment at both doses (Fig. 1B). Unlikely, the treatment of flutamide resulted in a significant increase of Cx30.3 gene expression (Fig. 1B). But, expressional change of $C \times 30.3$ gene between two flutamide-treated groups was not significantly different (Fig. 1B).

2. Expressional changes of $C \times 31$ and $C \times 31.1$ genes in the adult caudal epididymis treated with EB or flutamide at the weaning age

A significant increase of $C x 31$ expression was detected with a low-dose EB treatment (Fig. 2A). A further increase

of Cx31 transcript level was found in a high-dose EB treatment, and the increment of $C x 31$ expression by a highdose EB treatment was significantly higher than that by a low-dose EB treatment (Fig. 2A). Expression of Cx31 gene was also significantly increased by flutamide treatment (Fig. 2A). Like in case of EB treatment, a high-dose flutamide treatment resulted in more expression of $C \times 31$ gene than a low-dose flutamide treatment (Fig. 2A).

The EB treatments at different doses caused significant decreases of $C x 31.1$ gene expression, and there was no significant different on transcript level of $C \times 31.1$ gene by a low-dose and a high-dose EB treatments (Fig. 2B). In contrast, a significant increase of $C \times 31.1$ gene expression was found in a low-dose flutamide-treated group (Fig. 2B). The treatment of a high-dose flutamide resulted in a further increase of $C x 31.1$ transcript level in the adult caudal epididymis (Fig. 2B).
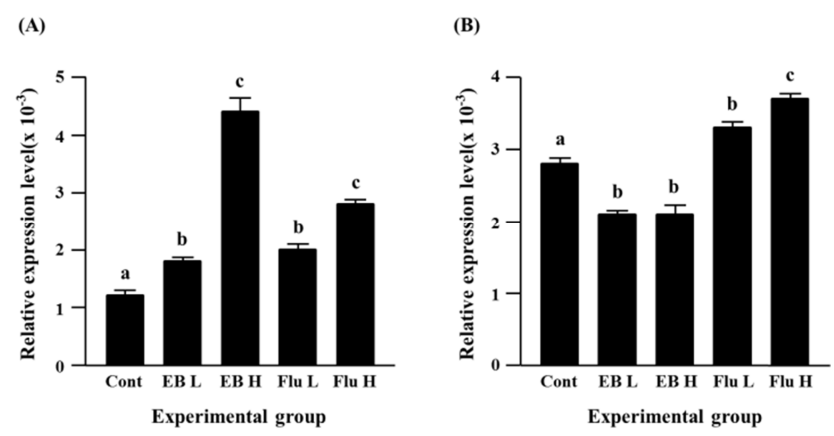

Fig. 2. Expressional changes of $C x 31$ and $C x 31.1$ in the caudal epididymis of adult rat treated with estradiol benzoate (EB) or flutamide (Flu) at the weaning age. Animals were subcutaneously injected with $\mathrm{EB}$ at a low dose $(0.015 \mathrm{mg} / \mathrm{kg}$ body weight, EB-L) or a high dose $(1.5 \mathrm{mg} / \mathrm{kg}$ body weight, EB-H) or Flu at a low dose $(500 \mathrm{mg} / \mathrm{kg}$ body weight, Flu-L) or at a high dose $(50 \mathrm{mg} / \mathrm{kg}$ body weight, Flu-H) at the weaning age. Control animals (Cont) were administrated with peanut oil. Different letters indicate statistical differences among control group and experimental groups in EB or Flu treatment group on transcript levels of $C \times 31$ (A) or $C \times 31.1$ (B). 
3. Expressional changes of $C \times 32$ and $C \times 37$ genes in the adult caudal epididymis treated with EB or flutamide at the weaning age

Expressional level of $C \times 32$ gene was significantly increased by EB treatment, even though there was no significant difference on the increment of $C x 32$ transcript levels between a low-dose and a high-dose EB treatment (Fig. 3A). The flutamide treatment also caused an increase of Cx32 transcript level (Fig. 3A). It is notable that an induction of $C x 32$ gene expression in a high-dose flutamide-treated group was about 10 times higher than that in control group (Fig. 3A).

The exposure to a low-dose EB resulted in a significant decrease of $C \times 37$ expression, while there was no significant change of $C x 37$ transcript level by a high-dose EB treatment, compared with the control (Fig. 3B). Transcript level of $C \times 37$ was significantly increased by a low-dose
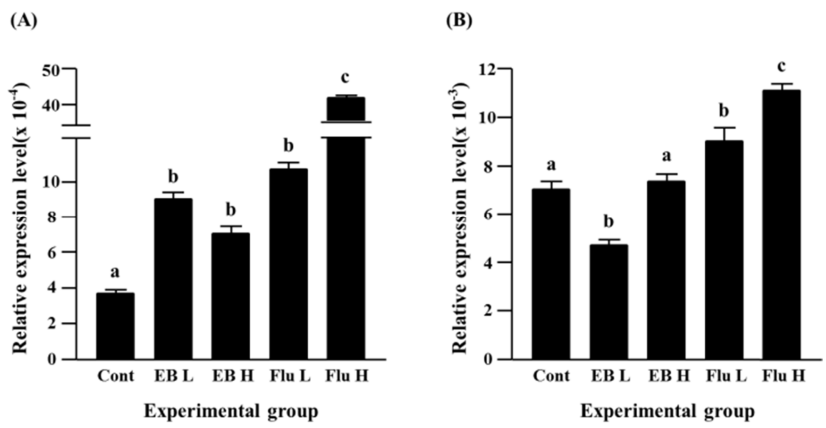

Fig. 3. Expressional changes of $C x 32$ and $C x 37$ in the caudal epididymis of adult rat treated with estradiol benzoate (EB) or flutamide (Flu) at the weaning age. Animals were subcutaneously injected with EB at a low dose $(0.015 \mathrm{mg} / \mathrm{kg}$ body weight, EB-L) or a high dose $(1.5 \mathrm{mg} / \mathrm{kg}$ body weight, EB-H) or Flu at a low dose $(500 \mathrm{mg} / \mathrm{kg}$ body weight, Flu-L) or at a high dose $(50 \mathrm{mg} / \mathrm{kg}$ body weight, Flu-H) at the weaning age. Control animals (Cont) were administrated with peanut oil. Different letters indicate statistical differences among control group and experimental groups in EB or Flu treatment group on transcript levels of $C \times 32$ (A) or $C x 37$ (B). flutamide treatment, and a further significant increase of Cx37 gene expression was observed in a high-dose flutamide-treated group (Fig. 3B).

\section{Expressional changes of $C x 40, C x 43$, and $C x 45$} genes in the adult caudal epididymis treated with EB or flutamide at the weaning age

The treatment of a low-dose EB didn't give on an influence on expression of $C x 40$, however a significantly
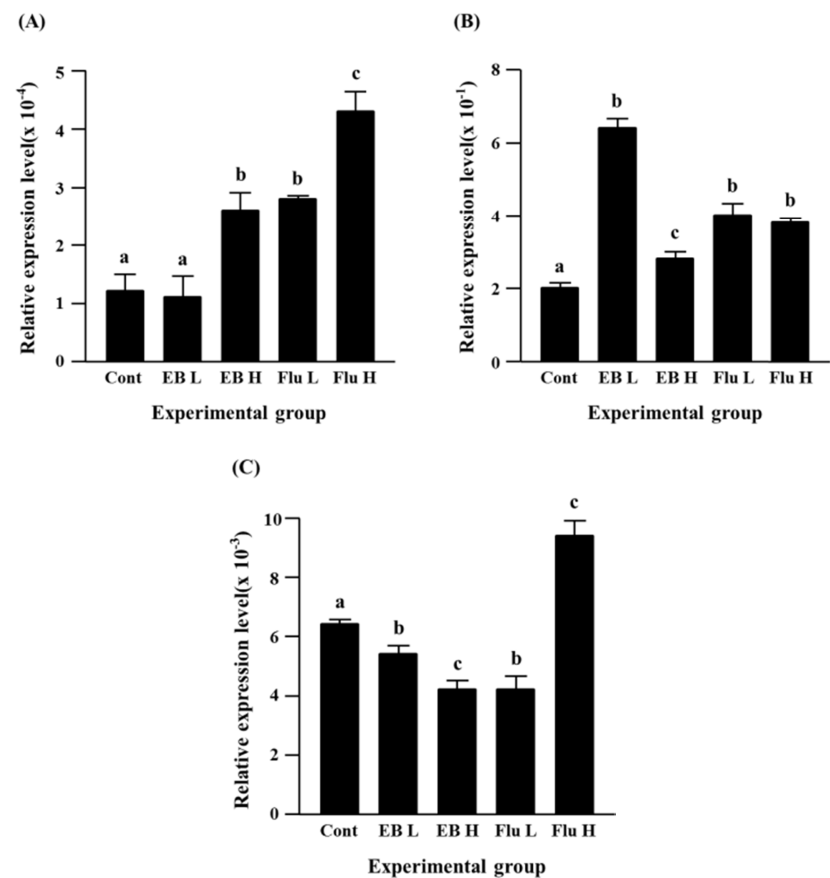

Fig. 4. Expressional changes of $C x 40, C x 43$, and $C x 45$ in the caudal epididymis of adult rat treated with estradiol benzoate (EB) or flutamide (Flu) at the weaning age. Animals were subcutaneously injected with EB at a low dose $(0.015 \mathrm{mg} / \mathrm{kg}$ body weight, EB-L) or a high dose $(1.5 \mathrm{mg} / \mathrm{kg}$ body weight, EB-H) or Flu at a low dose $(500 \mathrm{mg} / \mathrm{kg}$ body weight, Flu-L) or at a high dose $(50 \mathrm{mg} / \mathrm{kg}$ body weight, Flu-H) at the weaning age. Control animals (Cont) were administrated with peanut oil. Different letters indicate statistical differences among control group and experimental groups in EB or Flu treatment group on transcript levels of $C x 40$ (A), $C x 43$ (B), or $C x 45$ (C). 
increased expression of $C x 40$ gene was observed in a highdose EB-treated group (Fig. 4A). The flutamide treatments induced significant increases of $C x 40$ gene expression, and the increment of $C x 40$ transcript level was significantly higher in a high-dose flutamide treatment than a low-dose flutamide treatment (Fig. 4A).

The EB treatments resulted in significant increases of Cx43 transcript levels (Fig. 4B). The increment of $C x 43$ expression by a low-dose EB treatment was significantly higher than that by a high-dose EB treatment (Fig. 4B). The expression of $C x 43$ gene was also significantly increased by the exposure to flutamide, even though there was no significant difference on the transcript level of Cx43 gene between a low-dose flutamide group and a high-dose flutamide group (Fig. 4B).

The expression of $C x 45$ gene was suppressed by the EB treatment (Fig. 4C). A significant decrease of $C x 45$ transcript level was detected by a low-dose EB treatment, and a further decrease of $C x 45$ expression was found in a highdose EB group (Fig. 4C). Compared with the control, the transcript level of $C x 45$ gene was significantly decreased by a low-dose flutamide treatment, while a significant increase of $C x 45$ expression was found in a high-dose flutamide group (Fig. 4C).

\section{DISCUSSION}

Alteration of normal gene expression in the epididymis is frequently observed by the exogenous administration to steroidal agonistic and/or antagonistic compounds. Specially, exposure to such substances during the early postnatal period results in more evident outcomes in abnormal expression of various genes in the epididymis (Gorowska et al., 2014). The data from the present research clearly show that a single administration of EB or Flu at a weaning age is sufficient to disrupt normal expression of $C x$ isoforms in the adult caudal epididymis.

Segmental-specific expression patterns of $C x$ isoforms in the epididymis have been examined from our previous study (Lee, 2013). It is acceptable to consider that the findings from the current research should be compared with the outcomes conducted with same epididymal segment, rather than with those obtained from the different epididymal segment with same treatment. Thus, the significant findings driven from the present research have been evaluated with those from the treatment of EB or Flu at 7 days of postnatal age, previously reported (Lee, 2016).

The treatment of a low-dose EB at 7 days of age results in a significant increase of $C x 32$ transcript level and causes meaningful decreases of $C x 30.3, C x 31.1, C x 37$, and $C x 45$ transcript levels in the adult caudal epididymis (Lee, 2016). However, as observed in the present research, the same treatment at 21 days of age causes major increases of transcript levels of $C x 26, C \times 31, C x 37$, and $C x 43$ but significant reduction of $C \times 31.1$ and $C \times 45$ transcript amounts. Interestingly, expression of $C x 40$ is only not influenced by a low-dose EB treatment at any postnatal age. The low-dose EB treatments at different postnatal ages result in differential expression patterns of other $C x$ isoforms, except $C x 31.1$ and $C x 45$, in the adult caudal epididymis. At this point, any clear explanation is not suggested to describe such differential responses on the expression of $C x$ isoforms by same treatment of EB or Flu at different postnatal age. Atanassova et al (2001) show the regionaland postnatal age-specific expressional patterns of estrogen receptor alpha $(\mathrm{ER} \alpha)$ in the epididymis and vas deferens. In addition, they demonstrate the disruption of expressional patterns of ER $\alpha$ by neonatal exposure to diethylstilbestrol (Atanassova et al., 2001). In addition, Putz et al (2001) show that the neonatal EB treatment affects normal gene expression in the adult epididymis. Based on others' findings, it is proposed that the different postnatal time exposed to a low-dose EB would influence on the distinguishable expressional patterns of $C x$ isoforms in the adult caudal epididymis. Moreover, it could not rule out a 
possibility that expression of each $C x$ isoform would be differentially regulated by a low-dose EB due to its own specific responsiveness to EB, as shown in Hermoso et al's data (1997). Expressional changes of most $C x$ isoforms, except $C x 37$ and $C x 40$, by the treatment of a high-dose EB are not quite different with those by the treatment of a lowdose EB, even though there are some expressional variations of $C x 31, C x 43$, and $C x 45$ genes. There is no evident suggestion to describe such differential responses at some $C x$ isoforms to two EB concentrations. Detailed genomic analyses of $C x$ isoforms would be helpful to elucidate possible answers.

It is interested that the Flu treatments at two doses result in significant increases of transcript levels of all $C x$ isoforms, except a significant decrease of $C x 45$ transcript level by a low-dose Flu treatment. These observations slightly differ with those from the treatment of Flu at 7 days of age (Lee, 2016). The expressional level of androgen receptor (AR) in the epididymis is gradually increased with postnatal ages, especially during the early postpartum period (You \& Sar, 1998). In addition, the differentiation of the epididymal epithelial cells does not occur until the second week of postnatal age (Robaire et al., 2006). The columnar cell, a precursor of principal cell, first appears at the third week of postnatal age and becomes fully differentiated into basal cell and principal cell at the fourth week of postnatal age (Robaire et al., 2006). Because the differentiation of epithelial cells in the epididymis is under age-dependent manner, it is suggested that exogenous treatment of EB or Flu at different postnatal age could give an influence on the differentiation of the epididymal epithelial cells during the early postnatal period. The change of the epithelial differentiation in the epididymis would result in the modification of cellular composition and thus normal gene expression. Thus, it is reasonable to consider that the treatment of EB or Flu at different age during the early postnatal period causes different expressional patterns of $C x$ isoforms in the epididymis.

In conclusion, the present research shows that the exposure to steroidal agonist or antagonist at the weaning age could modify normal expression of $C x$ isoforms in the adult caudal epididymis. However, it could not be directly addressed from the current study if the EB or Flu treatment at the early postnatal age results in malfunction of the adult caudal epididymis. However, it is postulated that expressional changes of $C x$ isoforms induced by $\mathrm{EB}$ or Flu treatment would give disruptive impact on the epididymal function, even though the effect could be negligible.

\section{ACKNOWLEDGEMENT}

This research was supported by Basic Science Research Program through the National Research Foundation of Korea (NRF) funded by the Ministry of Education, Science and Technology (20090067187 and 20100022388).

\section{REFERENCES}

Atanassova N, McKinnell C, Williams K, Turner KJ, Fisher JS, Saunders PT, Millar MR, Sharpe RM (2001) Age-, cell- and region-specific immunoexpression of estrogen receptor alpha (but not estrogen receptor beta) during postnatal development of the epididymis and vas deferens of the rat and disruption of this pattern by neonatal treatment with diethylstilbestrol. Endocrinology 142:874-886.

Cry DG (2011) Connexins and pannexins: Coordinating cellular communication in the testis and epididymis. Spermatogenesis 1:325-338.

Cyr DG, Hermo L, Laird DW (1996) Immunocytochemical localization and regulation of connexin43 in the adult rat epididymis. Endocrinology 137:1474-1484. 
Goodenough DA. and Paul DL (2009) Gap junctions. Cold Spring Harb Perspect Biol 1:a003061.

Gorowska E, Zarzycka M, Chojnacka K, Bilinska B, Hejmej A (2014) Postnatal exposure to flutamide affects CDH1 and CTNNB1 gene expression in adult pig epididymis and prostate and alters metabolism of testosterone. Andrology 2:186-197.

Hermoso M, Sáez JC, Villalón M (1997) Identification of gap junctions in the oviduct and regulation of connexins during development and by sexual hormones. Eur J Cell Biol 74:1-9.

Lawrence TS, Beers WH, Gilula NB (1978) Transmission of hormonal stimulation by cell-to-cell communication. Nature 272:501-506.

Lee K-H (2013) Differential expression of multiple connexins in rat corpus and cauda epididymis at various postnatal stages. J Ani Sci Tech 55:521-530.

Lee K-H (2014) Expressional modulation of connexin isoforms in the initial segment of male rat treated with estradiol benzoate or flutamide. Dev Reprod 18:293300 .

Lee K-H (2015a) Exogenous exposure to estradiol benzoate or flutamide at the weaning age alters expression of connexin isoforms in the initial segment of male rat. Dev Reprod 19:43-51.

Lee K-H (2015b) Modification of gene expression of connexins in the rat corpus epididymis by estradiol benzoate or flutamide exposure at the early neonatal age. Dev Reprod 19:69-77.

Lee K-H (2016) Changes in expression of connexin isoforms in the caudal epididymis of adult Sprague-Dawley rats exposed to estradiol benzoate or flutamide at the neonatal age. Dev Reprod 20:237-245.
Putz O, Schwartz CB, LeBlanc GA, Cooper RL, Prins GS (2001) Neonatal low- and high-dose exposure to estradiol benzoate in the male rat: II. Effects on male puberty and the reproductive tract. Biol Reprod 65: 1506-1517.

Seo H-H, Seon C-W, Choi I, Cheon Y-P, Cheon T-H, LeeK-H (2010) Expressional profiling of connexin isoforms in the initial segment of the male reproductive tract during postnatal development. Reprod Dev Biol 34:103-109.

Robaire B, Hermo L (1988) Efferent ducts, epididymis, and vas deferens: structure, functions, and their regulation. In: Knobil E et al (eds.). The Physiology of Reproduction. Raven Press, New York, NY, pp 9991080.

Robaire B, Hinton BT, Orgebin-Crist MC (2006) The epididymis. In: Knobil E and Neil J (eds.) The Physiology of Reproduction, Elsevier, New York, NY pp 1071-1148.

St-Pierre N, Dufresne J, Rooney AA, Cyr DG (2003) Neonatal hypothyroidism alters the localization of gap junctional protein connexin 43 in the testis and messenger RNA levels in the epididymis of the rat. Biol Reprod 68:1232-1240.

Valiunas V, Polosina YY, Miller H, Potapova IA, Valiuniene L, Doronin S, Mathias RT, Robinson RB, Rosen MR, Cohen IS, Brink PR (2005) Connexin-specific cell-to-cell transfer of short interfering RNA by gap junctions. J Physiol 568:459-468.

You L, Sar M (1998) Androgen receptor expression in the testes and epididymides of prenatal and postnatal Sprague-Dawley rats. Endocrine 9:253-261. 